\title{
Improving Adherence and Quality of Life of CPAP for Obstructive Sleep Apnea With An Intervention Based On Stratification and Personalization of Care Plans: A Randomized Controlled Trial
}

\section{David Rudilla ( $\nabla$ david.rudilla@airliquide.com )}

Air Liquide Healthcare - Hospital Universitario de La Princesa https://orcid.org/0000-0002-6042-4724

\section{Salvador Perelló}

Hospital Universitario Joan XXIII (Tarragona - Spain)

\section{Pedro Landete}

Hospital Universitario de La Princesa (Madrid, Spain).

\section{Enrique Zamora}

Hospital Universitario de La Princesa (Madrid, Spain).

\section{María Vázquez}

Hospital Universitario Central de Asturias (Oviedo, Spain)

\section{Lluisa Sans}

Hospital Universitario Joan XXIII (Tarragona - Spain)

Jose Manuel Tomás

University of Valencia (Spain) Av. de Blasco Ibáñez

Jose Luis R Martín

Simplifying Research Institute

Jennifer Leonardi

Air Liquide Healthcare. C/ de Orense

\section{Gema Rubinos}

Hospital Universitario Central de Asturias (Oviedo, Spain) Av. Roma

\section{Julio Ancochea}

Hospital Universitario de La Princesa (Madrid, Spain).

\section{Research}

Keywords: CPAP, sleep apnoea/hypopnoea syndrome, adherence, RCT, quality of life, stratification

Posted Date: August 17th, 2021

DOI: https://doi.org/10.21203/rs.3.rs-757639/v1

License: (9) (1) This work is licensed under a Creative Commons Attribution 4.0 International License. Read Full License 


\section{Abstract \\ Purpose}

The aim was to determine adherence to CPAP and health-related outcomes in patients with OSA via a comprehensive program based on stratification and individualized care plans, including motivational interview.

\section{Methods}

A multicentre, randomized controlled trial (RCT) design was used in 3 hospitals. The control group followed the usual treatment. Intervention group (PIMA) followed the treatment with an adapted care plan (home visits, telephone, care-center) depending on socio-demographic, clinical and psychological variables, using motivational interviews in all the interventions. The main outcome was adherence, and secondary were quality of life, emotional state, activities, social relationships, perceived competence, and motivation. The clinical trial was registered with www.clinicaltrials.gov (NCT 04691479).

\section{Results}

213 patients ( $68.1 \%$ men, $58.7 \%$ between $51-69$ years old, $45.5 \%$ upper-secondary school education) were randomized: 108 were in the intervention group and 105 were in the control group. The result showed a statistically significant difference in adherence at 90 and 180 days respectively: 129.24 (IC 95\% 77.25-181.22) $p<0.0001$ and 288.30 (IC95\% 187.146-389.47) $p<0.0001$. The adherence (hours/day) showed favourable results for the PIMA group compared to the control group at 90 days with a difference of 1.74 hours/day (IC95\% 1.18-2.30) $p<0.0001$ and at 180 days with a difference of 2.31 (IC95\% 1.72-2.91) $p<0.001$. The results for secondary outcomes also showed statistically significant differences in favour of the PIMA group.

\section{Conclusions}

This study found evidence that a program based on stratification and personalized care plans, through motivational interviewing, improves adherence to CPAP treatment and health-related outcomes than traditional care.

\section{Introduction}

In obstructive sleep apnoea/hypopnoea syndrome (OSA), recurring episodes of obstruction are observed during sleep and are associated with daytime sleepiness [1]. The severity of this syndrome is assessed according to the number of events per hour of sleep, using the apnoea-hypopnoea index (AHI). OSA occurs in up to $24 \%$ of men [2], $7 \%$ of which experience daytime sleepiness, while OSA occurs in only $5 \%$ of women ${ }^{2}$. Lack of treatment is related to an increased risk of accidents, loss of quality of life and cardiovascular mortality [3].

Continuous positive airway pressure (CPAP) is the first-line treatment for moderate-to-severe OSA [4]. Most research considers a patient who uses CPAP a minimum of 4 hours a night during $70 \%$ of the week to be a good complier [5]. However, it is to a certain extent obvious, and it is also endorsed by studies [6], that 6 hours would be an excellent metric for adherence to optimize symptoms and obtain a clear reduction in blood pressure in hypertensive patients. 
Multidisciplinary approaches based on the study of behavioural changes together with continuous monitoring have shown promising results in improving patient adherence to CPAP intervention [7]. The current definition of adherence is largely arbitrary and is mainly used by third-party payers to determine CPAP reimbursement but CPAP adherence remains sub-optimal [8].

Patients may benefit from more individualized treatment, which can be done by reducing the risk of OSA consequences on a patient-to-patient basis. New strategies to augment adherence, especially early in the course of CPAP treatment, are needed in the management of OSA $[9,10]$.

Motivational interviewing (MI) is a technique that involves discussing treatment with patients in a way which empowers them to understand their individual therapy needs and drive them to address those. Different studies have demonstrated the usefulness of MI in the CPAP treatment of sleep apnea $[11,12]$. Therefore, it is very likely that MI, in combination with personalized patient interventions, could further improve adherence.

The aim of this study is to determine whether OSA patient adherence to CPAP can be improved using a comprehensive, multidisciplinary programme, based on a motivational change model and integration of predictive factors of adherence, to obtain a specific patient profile and therefore a personalized intervention plan.

\section{Materials And Methods}

\section{Design}

A multi-centre randomized, controlled trial (RCT) design was used, enrolling adult patients with OSA and a prescription for CPAP treatment from the Respiratory Medicine Department at La Princesa University Hospital (Madrid, Spain), Joan XXIII University Hospital (Tarragona, Spain) and Central University Hospital of Asturias (Oviedo, Spain), between May 2018 and June 2019. The study protocol was approved by the Clinical Research Ethics Committee at the participating hospitals (N. 3450; N96/19). The clinical trial was registered with www.clinicaltrials.gov (NCT 04691479).

\section{Patients}

The subjects enrolled in the study were required to have a diagnosis of OSA confirmed by sleep studies with polygraphy and/or polysomnography (criteria of the Spanish Sleep Society) and be naive to CPAP intervention. The study excluded subjects with obesity-related hypoventilation, severe COPD, cognitive disorders and those unable to understand the consent to participate. Prior to enrolment in the study, all patients were informed in detail about the study and signed the consent form to participate.

\section{Interventions}

A process was followed using a random number generator in SPSS to systematically assign patients to one group or another, with allocation concealment. Prescribers were responsible for randomization. See Fig. 1.

The control intervention group patients followed the standard of care. The therapy started in the hospital. The nurse performed training in the use of CPAP equipment, mask adjustment, safety, and maintenance. For follow-up, the patient was always referred to the Hospital, with a frequency established by the Spanish Society of Pulmonology and Thoracic Surgery (Days 30, 90 and 180). The follow-up procedure consisted of reviewing the CPAP hour-meter and resolving any, with the necessary corrective actions. 
The intervention group 'PIMA' (Spanish acronym: Plan Individualizado de Mejora de la Adherencia; Personalized Adherence Improvement Plan), began the treatment with the educational and training program "MEntA"

(Motivational Interview for Adherence) [12]. It consisted of one session with two blocks: educational activity and training activity. Also, the key to all patient interactions was the use of MI. In fact, the nurse used MI not only at the beginning of therapy, but also in every contact that the patient had with the patient throughout the treatment (subsequent follow-up visits, phone calls, etc.).

Subsequently, the nurse performed the stratification process, which determined the personalized intervention plan using two types of variables: personal and modulation. The variables of the stratification established the complexity and intensity of adaptations for the patient's treatment needs. Personal variables consider characteristics of the patient such as: age, level of studies, clinical (somnolence and apnoea-hypopnea index), and psychological (motivation and perceived competence). Modulation variables refer to characteristics ranging from the patient's environment (isochrone, which is the time the patient spends from home to the care center) to service options and preferences (for example, use of electronic applications, email, or visit preferences). The results are patients with the "a" profile (characterized by autonomy and mobility, predisposition to remote-controlled follow-up), patients with the "b" profile (need for more intensity in follow-up), or patients with the "c" profile (more difficulties to move around and require more intensive treatment). Profile "d" was applied to patients who were professional drivers, as they require specific interventions based on their occupation.

Regarding psychological variables for the evaluation of perceived competence, the Perceived Competence Evaluation Questionnaire validated in Adherence to CPAP in OSA (CEPCA) was used [13]. The scores obtained indicated the patient's feelings for self-effectiveness with the CPAP treatment. Motivation was also assessed, using the methodology defined in the Prochaska and DiClemente transtheoretical model [14], with an open-ended question to the patient which could be classified in five stages: precontemplation (very low motivation), contemplation (low motivation), determination (some motivation), active change (quite motivated) and maintenance (high motivation). Regarding the clinical variables, drowsiness was obtained through the administration of the Epworth Somnolence Test [15], and the apnoea-hypopnea index was taken from the patient's clinical history.

The personal and modulating variables were used to identify the degree of intensity the patient needed (channels and frequency of contact). The psychological and clinical variables obtained in this first visit were used as "predictive" information for patient adherence (either high, moderate or low). Subsequently, the care plan was initiated based on this information. Low or moderate adherence care plans were more intensive than high adherence relative care plans. In Table 1 we can see how the patient's profile (a, b, c or d) and the level of adherence determine the care plan. 
Table 1

PIMA Care Plans: profile, level of adherence and general interventions

\begin{tabular}{|c|c|c|c|}
\hline Profile & High Adherence & Moderate Adherence & Low Adherence \\
\hline a & $\begin{array}{l}\text { Channels: Phone-call } \\
\text { Frequencies: } \\
\text {-90 days: moderate } \\
\text {-after } 90 \text { days: low } \\
\text { Contents: Positive } \\
\text { motivational } \\
\text { reinforcement }\end{array}$ & $\begin{array}{l}\text { Channels: Phone-call \& Care } \\
\text { Center } \\
\text { Frequencies: } \\
\text {-90 days: intensive } \\
\text {-after } 90 \text { days: moderate } \\
\text { Contents: Motivational } \\
\text { interview, functional analysis }\end{array}$ & $\begin{array}{l}\text { Channels: Phone-call \& Care Center } \\
\text { Frequencies: Intensive } \\
\text { Contents: Motivational interview, training } \\
\text { and educational reinforcement } \\
\text { Telemonitoring }\end{array}$ \\
\hline b & $\begin{array}{l}\text { Channels: Phone-call \& } \\
\text { Care Center } \\
\text { Frequencies: } \\
\text {-90 days: moderate } \\
\text {-after } 90 \text { days: low } \\
\text { Contents: Positive } \\
\text { motivational } \\
\text { reinforcement }\end{array}$ & $\begin{array}{l}\text { Channels: Care Center } \\
\text { Frequencies: } \\
\text {-90 days: intensive } \\
\text {-after } 90 \text { days: moderate } \\
\text { Contents: Motivational } \\
\text { interview, functional analysis }\end{array}$ & $\begin{array}{l}\text { Channels: Care Center } \\
\text { Frequencies: Intensive } \\
\text { Contents: Motivational interview, training } \\
\text { and educational reinforcement } \\
\text { Telemonitoring }\end{array}$ \\
\hline C & $\begin{array}{l}\text { Channels: Home } \\
\text { Frequencies: } \\
\text {-90 days: moderate } \\
\text {-after } 90 \text { days: low } \\
\text { Contents: Positive } \\
\text { motivational } \\
\text { reinforcement }\end{array}$ & $\begin{array}{l}\text { Channels: Home } \\
\text { Frequencies: } \\
\text {-90 days: intensive } \\
\text {-after } 90 \text { days: moderate } \\
\text { Contents: Motivational } \\
\text { interview, functional analysis }\end{array}$ & $\begin{array}{l}\text { Channels: Home } \\
\text { Frequencies: Intensive } \\
\text { Contents: Motivational interview, training } \\
\text { and educational reinforcement } \\
\text { Telemonitoring }\end{array}$ \\
\hline d & $\begin{array}{l}\text { Channels: Phone-call } \\
\text { Frequencies: } \\
\text {-90 days: moderate } \\
\text {-after } 90 \text { days: low } \\
\text { Contents: Positive } \\
\text { motivational } \\
\text { reinforcement } \\
\text { Telemonitoring }\end{array}$ & $\begin{array}{l}\text { Channels: Phone-call \& Care } \\
\text { Center } \\
\text { Frequencies: } \\
\text {-90 days: intensive } \\
\text {-after } 90 \text { days: moderate } \\
\text { Contents: Motivational } \\
\text { interview, functional analysis } \\
\text { Telemonitoring }\end{array}$ & $\begin{array}{l}\text { Channels: Care Center \& Home } \\
\text { Frequencies: Intensive } \\
\text { Contents: Motivational interview, training } \\
\text { and educational reinforcement } \\
\text { Telemonitoring }\end{array}$ \\
\hline
\end{tabular}

In follow-up visits, psychological and clinical variables were reviewed and the patient's adherence was added (the profile always remains the same, since their personal characteristics are generally stable). Based on the level of adherence, the care plan was adapted if the patient's situation had changed. For patients with low adherence, telemonitoring was used to measure hours of adherence, AHI and air leaks. Once the follow-up procedure with telemonitoring of 1 month had started, every 10 days, the patient evolution was reviewed. The level of adherence 
determine the frequencies of interventions, taking into account short term (first 90 days of treatment) and after day 90. This configuration allows, on the one hand, the dedication of resources to patients who need more care, and on the other hand, the long-term management of large volumes of patients.

Several outcomes were included in this study. First, adherence to CPAP therapy after 90, 180 and 365 days of treatment was assessed as the primary outcome. The total number of night-time hours during which the CPAP device was used at a therapeutic pressure was recorded by specific counters within each device and were collected during the study follow-up period. In terms of secondary outcomes, quality of life was assessed using the Visual Analogical Well-being Scale for apnoea [16] and sleepiness was assessed using the Epworth Sleepiness Scale [15]. Motivation was also assessed, as defined in the transtheoretical model [14] using an open-ended question to the patient, which could be classified in the five stages. Moreover, three health related outcomes (mood, activities, social relationships) were also measured using the following ad hoc question "Taking into account your sleep problems, how would you say you are in terms of mood/activities/social relationships?". The answer alternatives were: Good, Normal/no change, Bad.

\section{Statistical analysis}

The sample size was determined based on a previous moderate effect size of .06 because there was no prior literature available with similar characteristics to those proposed in this study. As such, with an alpha value of .05 and a maximum beta error of .20, a total number of 70 subjects were established, which was increased considerably in order to compensate for possible experimental mortality in the study and to reduce the variability of the measures being studied.

Statistical analysis is based on intent-to-treat (ITT) analysis of the participants. A descriptive analysis of the demographic and clinical characteristics of all patients enrolled in the study was performed, as well as a baseline analysis comparing both study groups after randomization. The statistical inference analyses were performed using both parametric (t-student for independent groups) and non-parametric (U-Mann Whitney) models for continuous variables, and crosstab analysis for categorical data. The analyses were performed for the comparison of study groups at two cut-off time points (90 and 180 days) and an ad hoc analysis at one year of follow-up for the most important variables. The Chi-square statistic was used for comparing all categories at one year adherence analysis. The alpha value was 0.05 and all analyses were performed on two-tails. The statistical software used was SPSS V26.

\section{Results}

\section{Descriptive statistics}

A total of 213 patients were randomized between the two groups (PIMA and Control) (Fig. 2) of whom 108 were in the intervention group and 105 were in the control group. $68.1 \%$ were men, $58.7 \%$ of the study sample were aged between 51 and 69, and 45.5\% had upper-secondary school education. Tests performed to compare control and PIMA groups at the beginning of the RCT showed that groups were equivalent for all baseline variables. Table 2 provides descriptive characteristics of the participants. 
Table 2

Baseline characteristics of the participants.

\begin{tabular}{|c|c|c|c|c|c|c|c|c|c|}
\hline \multirow[t]{2}{*}{ VARIABLE } & \multicolumn{2}{|c|}{$\begin{array}{l}\text { TOTAL SAMPLE }(n= \\
\text { 213) }\end{array}$} & \multicolumn{2}{|c|}{$\begin{array}{l}\text { PIMA GROUP } \\
(n=108)\end{array}$} & \multicolumn{2}{|c|}{$\begin{array}{l}\text { CONTROL GROUP } \\
(n=105)\end{array}$} & \multirow[t]{2}{*}{ test } & \multirow[t]{2}{*}{ df } & \multirow[t]{2}{*}{$P$} \\
\hline & $\begin{array}{l}\text { Frequency } \\
\text { (\%) }\end{array}$ & $\begin{array}{l}\text { Mean } \\
\text { (SD) }\end{array}$ & $\begin{array}{l}\text { Frequency } \\
\text { (\%) }\end{array}$ & $\begin{array}{l}\text { Mean } \\
\text { (SD) }\end{array}$ & $\begin{array}{l}\text { Frequency } \\
\text { (\%) }\end{array}$ & $\begin{array}{l}\text { Mean } \\
\text { (SD) }\end{array}$ & & & \\
\hline Sex (male) & $145(68.1)$ & & $72(66)$ & & 73 (69.5) & & 0.200 & 1 & .655 \\
\hline Age by groups & & & & & & & 1.79 & .407 & \\
\hline$<50$ years & $53(24.9)$ & & $23(21.30)$ & & $30(28.6)$ & & & & \\
\hline $51-69$ years & $125(58.7)$ & & $65(60.2)$ & & $60(57.1)$ & & & & \\
\hline$>70$ years & 35 (16.4) & & $20(18.5)$ & & $15(14.3)$ & & & & \\
\hline BMI by categor & & & & & & & 4.695 & 6 & .584 \\
\hline $\begin{array}{l}\text { Normal } \\
\text { weight }\end{array}$ & $18(8.5)$ & & $8(7.4)$ & & $10(9.5)$ & & & & \\
\hline Overweight & $62(29.1)$ & & $28(26)$ & & $34(32.4)$ & & & & \\
\hline Obesity & $131(61.5)$ & & $71(65.8)$ & & $60(57.1)$ & & & & \\
\hline Missed & $2(0.9)$ & & $1(0.9)$ & & $1(0.9)$ & & & & \\
\hline Severity OSA & & & & & & & -.922 & 211 & .357 \\
\hline Mild & $7(3.3)$ & & $6(5.6)$ & & $1(0.9)$ & & & & \\
\hline Moderate & $27(12.7)$ & & $12(11.1)$ & & $15(14.3)$ & & & & \\
\hline Severe & 179 (84) & & $90(83.3)$ & & $89(84.8)$ & & & & \\
\hline $\begin{array}{l}\text { Apnea- } \\
\text { hypopnea } \\
\text { index }\end{array}$ & & $\begin{array}{l}41.98 \\
(20.28)\end{array}$ & & $\begin{array}{l}40.71 \\
(16.35)\end{array}$ & & $\begin{array}{l}43.29 \\
(23.66)\end{array}$ & & & \\
\hline Reason for con & sultation & & & & & & 2.59 & 2 & .274 \\
\hline Individual & 72 & $(33.8)$ & $41(38)$ & & 31 (29.5) & & & & \\
\hline Derivation & 52 & $(24.4)$ & $22(20.4)$ & & $30(28.5)$ & & & & \\
\hline $\begin{array}{l}\text { Familiar } \\
\text { surroundings }\end{array}$ & 89 & $(41.8)$ & $45(41.7)$ & & $44(42)$ & & & & \\
\hline $\begin{array}{l}\text { Quality of } \\
\text { life }\end{array}$ & & $\begin{array}{l}5.24 \\
(2.23)\end{array}$ & & $\begin{array}{l}5.45 \\
(2.30)\end{array}$ & & $\begin{array}{l}5.02 \\
(2.14)\end{array}$ & 1.423 & 211 & .156 \\
\hline Comorbidity & & & & & & & 1.694 & 3 & .638 \\
\hline Physical & $122(57.3)$ & & $61(56.5)$ & & $61(58.1)$ & & & & \\
\hline Psychic & $11(5.2)$ & & $4(3.7)$ & & 7 (7) & & & & \\
\hline
\end{tabular}

BMI: Body mass index. 


\begin{tabular}{|c|c|c|c|c|c|c|c|c|c|}
\hline \multirow[t]{2}{*}{ VARIABLE } & \multicolumn{2}{|c|}{$\begin{array}{l}\text { TOTAL SAMPLE }(n= \\
\text { 213) }\end{array}$} & \multicolumn{2}{|c|}{$\begin{array}{l}\text { PIMA GROUP } \\
(n=108)\end{array}$} & \multicolumn{2}{|c|}{$\begin{array}{l}\text { CONTROL GROUP } \\
(n=105)\end{array}$} & \multirow[t]{2}{*}{ test } & \multirow[t]{2}{*}{ df } & \multirow[t]{2}{*}{$P$} \\
\hline & $\begin{array}{l}\text { Frequency } \\
(\%)\end{array}$ & $\begin{array}{l}\text { Mean } \\
\text { (SD) }\end{array}$ & $\begin{array}{l}\text { Frequency } \\
(\%)\end{array}$ & $\begin{array}{l}\text { Mean } \\
\text { (SD) }\end{array}$ & $\begin{array}{l}\text { Frequency } \\
(\%)\end{array}$ & $\begin{array}{l}\text { Mean } \\
\text { (SD) }\end{array}$ & & & \\
\hline None & $80(37.6)$ & & $43(40)$ & & $37(35.2)$ & & & & \\
\hline Drowsiness & & $\begin{array}{l}11.57 \\
(5.22)\end{array}$ & & $\begin{array}{l}11.61 \\
(5.15)\end{array}$ & & $\begin{array}{l}11.53 \\
(5.31)\end{array}$ & 0.108 & 211 & .914 \\
\hline \multicolumn{3}{|c|}{ Educational levels } & & & & & 2.277 & 2 & .320 \\
\hline High & $41(19.2)$ & & $25(23.1)$ & & $16(15.2)$ & & & & \\
\hline Medium & $97(45.5)$ & & $48(44.4)$ & & 49 (46.7) & & & & \\
\hline Low & 75 (35.2) & & $35(32.4)$ & & $40(38.1)$ & & & & \\
\hline Isochrone & & & & & & & 2.045 & 2 & .360 \\
\hline$<30^{\prime}$ & $\begin{array}{l}196( \\
92.0)\end{array}$ & & 99 (91.7) & & 97 (92.4) & & & & \\
\hline $30-60^{\prime}$ & $15(7.0)$ & & $7(6.5)$ & & $8(7.6)$ & & & & \\
\hline$>60^{\prime}$ & $2(0.9)$ & & $2(1.9)$ & & $(0.0)$ & & & & \\
\hline \multicolumn{3}{|c|}{ Use digital tools } & & & & & 0.223 & 2 & .895 \\
\hline $\begin{array}{l}\text { App + email } \\
\text { + Internet }\end{array}$ & $137(64.3)$ & & $68(63)$ & & $69(65.8)$ & & & & \\
\hline Internet & 37 (17.4) & & 19 (17.6) & & $18(17.1)$ & & & & \\
\hline None & $39(18.3)$ & & $21(19.5)$ & & $18(17.1)$ & & & & \\
\hline \multirow[t]{5}{*}{ Profile } & & & & & & & 4.537 & 3 & .209 \\
\hline & 66.7 & a & 64.8 & & 68.6 & & & & \\
\hline & 22.5 & $b$ & 25.0 & & 20.0 & & & & \\
\hline & 9.4 & c & 7.4 & & 11.4 & & & & \\
\hline & 1.4 & $d$ & 2.8 & & 0.0 & & & & \\
\hline Mood & & & & & & & 1.461 & 2 & .482 \\
\hline Bad & $44(20.7)$ & & $20(18.5)$ & & $24(22.9)$ & & & & \\
\hline $\begin{array}{l}\text { Normal/no } \\
\text { change }\end{array}$ & $126(59.2)$ & & $63(58.3)$ & & $63(60)$ & & & & \\
\hline Good & $43(20.2)$ & & $25(23.1)$ & & $18(17.1)$ & & & & \\
\hline \multicolumn{3}{|c|}{ Daily life activities } & & & & & .977 & 2 & .614 \\
\hline Bad & $64(30)$ & & $31(28.8)$ & & $33(31.4)$ & & & & \\
\hline
\end{tabular}




\begin{tabular}{|c|c|c|c|c|c|c|c|c|c|}
\hline \multirow[t]{2}{*}{ VARIABLE } & \multicolumn{2}{|c|}{$\begin{array}{l}\text { TOTAL SAMPLE }(n= \\
213)\end{array}$} & \multicolumn{2}{|c|}{$\begin{array}{l}\text { PIMA GROUP } \\
(n=108)\end{array}$} & \multicolumn{2}{|c|}{$\begin{array}{l}\text { CONTROL GROUP } \\
(n=105)\end{array}$} & \multirow[t]{2}{*}{ test } & \multirow[t]{2}{*}{ df } & \multirow[t]{2}{*}{$P$} \\
\hline & $\begin{array}{l}\text { Frequency } \\
(\%)\end{array}$ & $\begin{array}{l}\text { Mean } \\
\text { (SD) }\end{array}$ & $\begin{array}{l}\text { Frequency } \\
\text { (\%) }\end{array}$ & $\begin{array}{l}\text { Mean } \\
\text { (SD) }\end{array}$ & $\begin{array}{l}\text { Frequency } \\
\text { (\%) }\end{array}$ & $\begin{array}{l}\text { Mean } \\
\text { (SD) }\end{array}$ & & & \\
\hline $\begin{array}{l}\text { Normal/no } \\
\text { change }\end{array}$ & $111(52.1)$ & & $55(51.1)$ & & $56(53.3)$ & & & & \\
\hline Good & $38(17.8)$ & & $22(20.3)$ & & $16(15.2)$ & & & & \\
\hline \multicolumn{3}{|c|}{ Social relationships } & & & & & .301 & 2 & .860 \\
\hline Bad & 39 (18.3) & & 20 (18.5) & & $19(18.1)$ & & & & \\
\hline $\begin{array}{l}\text { Normal/no } \\
\text { change }\end{array}$ & $145(68.1)$ & & $72(66.7)$ & & $73(69.6)$ & & & & \\
\hline Good & $29(13.6)$ & & 16 (14.9) & & $13(12.4)$ & & & & \\
\hline
\end{tabular}

A total of $9.85 \%$ (21 subjects) withdrew from the study. The percentage of withdrawals in the PIMA group was $10.18 \%$ ( 11 subjects) while in the control group it was $9.52 \%$ (10 subjects). In the PIMA group, the reasons for this were: 8 subjects for clinical reasons (changes of treatment), 2 lost, 1 abandoned. In the control group, 7 patients withdrew because of voluntary abandonment and 3 patients were lost. None of the withdrawals were due to possible adverse effects.

\section{Inferential statistics results.}

The mean adherence was compared between the study groups during therapy follow-up. The result showed a statistically significant difference at 90 and 180 days respectively: 129.24 (IC95\% 77.25-181.22) $p<0.0001$ and 288.30 (IC95\% 187.146-389.47) $p<0.0001$. These results were also confirmed by non-parametric analysis. Also, the number of hours of sleep per day indicated positive results for the study intervention compared to the control group at 90 days with an improvement of of 1.74 hours per day (IC95\% 1.18-2.30) $p<0.0001$ and at 180 days with an improvement of 2.31 hours per day (IC95\% 1.72-2.91) $p<0.001$. Moreover, patients in the PIMA group showed an increase in hours of sleep per day of 0.53 (IC95\% 0.032-1.04) $p<0.05$ between days 90 and 180 , whereas patients in the control group did not result in increased average sleep per day between these time points. This was also confirmed by non-parametric analysis: $p<0.01$. Table 3 for complete results. 
Table 3

Adherence results for PIMA vs control group.

\begin{tabular}{|llllllll|}
\hline VARIABLE & \multicolumn{2}{l}{ PIMA } & \multicolumn{3}{l}{ CONTROL } & p-value \\
\cline { 2 - 8 } & N & MEAN & SD & N & MEAN & SD & \\
\hline Adherence 90 days & 101 & 494.812 & 158.63 & 95 & 365.572 & 15.78 & $<0.0001$ \\
\hline Adherence 180 days & 97 & 987.608 & 312.719 & 97 & 699.300 & 396.475 & $<0.0001$ \\
\hline Adherence h/d 90 days & 102 & 5.80 & 1.63 & 95 & 4.06 & 2.28 & $<0.0001$ \\
\hline Adherence h/d 180 days & 99 & 6.33 & 1.99 & 97 & 4.01 & 2.23 & $<0.0001$ \\
\hline Change h/d 90 vs 180 days & 99 & 0.52 & 1.81 & 93 & -0.01 & 1.73 & $=0.037$ \\
\hline Adherence one year & 96 & 2161.71 & 864.43 & 87 & 1661.21 & 887.22 & $<0.0001$ \\
\hline Adherence h/d one year & 96 & 5.92 & 2.37 & 87 & 4.55 & 2.43 & $<0.0001$ \\
\hline Quality of life one year & 96 & 8.69 & 1.66 & 86 & 7.67 & 1.59 & $<0.0001$ \\
\hline h/d: hours per day. SD: standard deviation. & & & & & \\
\hline
\end{tabular}

The secondary outcomes also showed statistically significant improvement for the PIMA group patients for all measures evaluated. The quality of life at 90 days was 2.56 higher in the PIMA group (IC95\% 2.03-3.08) p $<0.0001$ and at 180 days was 0.20 higher (IC95\% $0.74-1.56) p<0.0001$, see Fig. 3 . The patient state of mind was evaluated using three categories and showed that 73 of 102 patients (71.5\%) in the PIMA group reached the best score at 90 days compared with only 28 of 95 patients $(29.5 \%)$ in the control group $p<0.0001$ at that same time point. Similar results were found for daily life activities with 63 and 33 patients reaching the best category for PIMA and control groups respectively $p<0.0001$. The frequency of social relationships showed a statistically significant difference between groups at both 90 and 180 days $p<0.0001$ ) (see Fig. 4). Similar results were found for evaluation of state of mind at 180 days, indicating that 84 patients ( $85 \%$ ) in the PIMA group reached the best score compared with 52 $(53.6 \%)$ in the control group $p<0.0001$. For daily life activities at 180 days the data showed that 79 out of 99 patients $(80 \%)$ for PIMA group were active compared with 53 out of 97 patients $(55 \%)$ in the control group $p<$ 0.0001 .

It is also interesting to consider communication channels used for the patient interventions, since this will determine resources required to provide support. Thus, at 90 days the use of telephone as the main communication channel was used by $31.4 \%$ of patients in the PIMA group while $64 \%$ of this group preferred a meeting point. On the contrary, for the control group, all subjects preferred the meeting point $p<0.0001$. However, after 180 days of follow up $96 \%$ of patients in the PIMA group were using the telephone as their first communication channel compared with $0 \%$ of patients in the control group $p<0.0001$. Also, the number of unscheduled calls during the follow up showed a mean of 0.19 (SD 0.57) for the PIMA patients compared with $0.41(0.73)$ those for control patients, $p=0.003$ for non-parametric analysis.

The Epworth Somnolence Test results collected from patients after 180 days a mean difference between groups of -3.12 (IC95\% -3.98 to -2.26) p < 0.0001, with the a mean value of 2.03 for the PIMA group compared with 5.15 for the control group. The motivation score for the first cut-off showed 49 patients in the PIMA group (45\%) were quite motivated in contrast to 36 patients (34.2\%) in the control group $p<0.001$. Evaluation at day 90 showed 75 (73.5\%) 
patients in maintenance (high motivation) in the PIMA group compared with 21 patients (22.1\%) from the control group $p<0.0001$. Measurement at day 180 showed an increase in maintenance patients in the PIMA group (85 patients, $85.9 \%)$, while for the control group, this figure only increased to 25 patients $(25.8 \%), p<0.0001$.

An ad hoc analysis at one year of follow-up still showed statistically significant differences between the PIMA and control groups for the main variables (Tables 3 and 4).80\% of patients were compliant at day 365 in the PIMA group compared with $66.3 \%$ in the control group. The improvement in overall adherence to CPAP therapy in the PIMA intervention group is clearly demonstrated. At Day 365 , the $\%$ of non-compliers in the PIMA and control groups were $20 \%$ and $33.7 \%$ respectively. The decrease in non-adherence can also be observed at earlier time-points during the study, where the \% of non-compliers at Day 90 and D180 were $11.8 \%$ compared with $45.7 \%$ and $18.2 \%$ compared with $38.9 \%$ in the PIMA and control groups respectively.

Table 4

Compliance categories for adherence results at one year

\begin{tabular}{|lllllll|}
\hline $\begin{array}{l}\text { Adherence Category at Day } \\
\mathbf{3 6 5}\end{array}$ & $\begin{array}{l}\text { PIMA } \\
\mathbf{N}\end{array}$ & $\begin{array}{l}\text { Control } \\
\mathbf{N}\end{array}$ & $\begin{array}{l}\text { PIMA } \\
(\%)\end{array}$ & $\begin{array}{l}\text { Control } \\
(\%)\end{array}$ & Difference & \\
\hline$>=6 \mathrm{~h} /$ day & 51 & 29 & $53.7 \%$ & $34.9 \%$ & 18.8 & Adherent \\
\hline$>=4$ and $<6$ h / day & 25 & 26 & $26.3 \%$ & $31.3 \%$ & -5 & Adherent \\
\hline$>=2$ and $<4$ h / day & 14 & 7 & $14.7 \%$ & $8.4 \%$ & 6.3 & $\begin{array}{l}\text { Non- } \\
\text { Adherent }\end{array}$ \\
\hline$<2$ h / day & 5 & 21 & $5.3 \%$ & $25.3 \%$ & -20 & $\begin{array}{l}\text { Non- } \\
\text { Adherent }\end{array}$ \\
\hline Total & 55 & 83 & $100 \%$ & $100 \%$ & & \\
\hline
\end{tabular}

The largest impact of the PIMA intervention on the improvement of adherence to CPAP therapy is observed in the group of subjects with adherence $<2 \mathrm{~h} /$ day, more so than any higher adherence time category. This is also consistent across all time points.

\section{Discussion}

This study has found evidence that a programme based on stratification labels for patients to obtain personalized care plans, achieves a higher level of efficacy in adherence to the CPAP intervention, as well as an improvement in quality of life, emotional state and motivation, when compared to the standard of care intervention. The data observed in this study shows how an approach that stratifies OSA patients based on objective measurements is highly useful in determining specific plans according to subject profiles and thereby improves adherence with the CPAP intervention.

The results obtained through clinical trials, which have been widely discussed, range from increased number of hours of sleep, quality of life and social relationships, to improvements in cognitive performance and reduced mortality [17]. However, the efficacy of CPAP interventions depends on proper adherence and given its specific conditions of use, this aspect still requires a significant level of research, since it has been observed that, in the past 
20 years, the percentage of subjects who do not manage to reach 7 hours of night-time sleep while using this intervention has remained constant at around $34 \%$ of subjects [18].

The results of our research show that the stratification procedure, based on which a personalized adherence improvement plan is put in place, is able to maintain adherence with the therapy for up to 180 days compared to the usual practice for monitoring this type of patient undergoing CPAP intervention. The PIMA programme improves therapeutic adherence by raising patient awareness and adjusting care to consider changes in their lifestyle and technological advances such as telemonitoring $[7,11,19]$. Previous studies have shown the importance of examination before prescription, due to the influence of anatomical differences in terms of adherence [20]. It has also been observed that the success of long-term adherence is conditioned, to a large extent, by the patient's behaviour during the first two weeks [21] together with the immediate social support they receive [22]. Similarly, the use of new technologies, such as telemonitoring enables early intervention with alerts to complications or changes in use [23]. However, the indiscriminate use of telemonitoring does not provide benefits in terms of adherence, and it seems to be more indicated in situations of early detection or identification of barriers to adherence and to certain profiles that present a specific clinical picture and specific situation [24].

An important aspect is the cost-benefit impact of an intervention based on personalization of care. PIMA allows sustainability since with stratification and segmentation, it is identified which patients need more attention, without forgetting the long-term treatment of the rest of the patients.

As a patient's pattern of adherence is evident within the first weeks of CPAP treatment, it is highly likely that patients have already formed perceptions regarding the seriousness of OSA and the benefit of treatment, and thus these cognitions influence adherence [23]. Education is one way to enhance self-efficacy. MEntA, the educational program used by the PIMA programme is based on the motivational interview, for which there is also extensive evidence on its efficacy in health interventions $[19,25]$. The factors which the aforementioned studies determine as being predictive of proper adherence are complemented in the PIMA model by the Transtheoretical Model of Change, in its version adapted to sleep apnoea treatment, from the initial version created to predict smoking cessation [26].

Studies have observed that beliefs related to the pathology or efficacy of the treatment, together with the perception of self-efficacy in terms of confidence in starting the treatment and in beliefs regarding proper interaction with the environment, explain an up to $30 \%$ difference in the use of the CPAP intervention [27]. A high level of adherence is associated with an internal locus of control [25] (subjects who believe they are in control of their own situation are more likely to take on board the advice provided by the physician) increasing adherence to CPAP [28]. Motivated patients have a higher level of adherence to CPAP [29]. This also applies to subjects with social support, with an improvement in sleep quality and quality of life also being observed in the person sharing a bed with the patient [30]. All of these predictive factors are included in the framework of the PIMA programme and were used to determine the label for each patient and the degree of personalization included to monitor them.

The PIMA intervention in our study was based on a broad, multidisciplinary framework with the aim of personalizing the approach needed by each patient in terms of improving adherence to CPAP. This intervention strives to change the patient's perception of the difficulties and drawbacks of the proposed therapy, as well as their possible risks and ability to use it. To this end, these results not only show an improvement in the adherence, but also show statistically significant correlations between this adherence and positive correlates such as quality of life 
and activities. Statistically significant relationships were observed between adherence and patients-reportedoutcomes (PROs). These variables are highly related to the efficacy of the CPAP therapy.

The limitations of this study include the study duration, which, although at 1 year is longer than many studies, does not provide insight into longer-term changes and behaviour maintenance.

\section{Conclusions}

The PIMA model summarizes and quantifies the most relevant aspects to be considered in caring for CPAP therapy patients. It provides a specific profile for each patient aiming to provide personalized care with the help of new information technologies. Ultimately, this methodology improves OSA patients' adherence to CPAP therapy, thereby improving their quality of life and everyday living conditions. Improvement in adherence to CPAP therapy leads to an overall lower burden of disease and decreased costs associated with events arising from poorly-managed OSAS.

\section{Declarations}

Funding sources: Not applicable

Conflicts of Interest: The authors declare that there are no conflicts of interest.

Availability of data and material: Data available on request from the authors

Code availability: Not applicable

Ethics approval: This study was performed in line with the principles of the Declaration of Helsinki. Approval was granted by the Clinical Research Ethics Committee of Hospital Universitario de La Princesa (N.3450) and Hospital Universitario Central de Asturias 8N96/19).

Consent to Participate: All participants in this study gave their written informed consent to participate.

Consent to Publish: All participants in this study gave their written informed consent for the publication of the results.

\section{References}

1. Riha RL. Diagnostic approaches to respiratory sleep disorders. J Thorac Dis. 2015;7(8):1373-84.

2. Garvey JF, Pengo MF, Drakatos P, et al. Epidemiological aspects of obstructive sleep apnea. J Thorac Dis. 2015;7(5):920-9.

3. Leung RS, Bradley TD. Sleep apnea and cardiovascular disease. Am J Respir Crit Care Med. 2001;164(12):2147-65.

4. Grupo Español de Sueño. Consenso Nacional sobre el syndrome de apneas-Hipopneas del sueño (OSA). Arch Bronc. 2005;41(S4):7-9.

5. Sawyer AM, Gooneratne NS, Marcus CL, et al. A systematic review of CPAP adherence across age groups: clinical and empiric insights for developing CPAP adherence interventions. Sleep Med Rev. 2011;15(6):343-56. 
6. Weaver TE, Maislin G, Dinges DF, Bloxham T, George CF, Greenberg H, Kader G, Mahowald M, Younger J, Pack Al. Relationship between hours of CPAP use and achieving normal levels of sleepiness and daily functioning. Sleep. 2007;30:711-9.

7. Hwang D, Chang JW, Benjafield AV, et al. Effect of Telemedicine Education and Telemonitoring on Continuous Positive Airway Pressure Adherence. The Tele-OSA Randomized Trial. Am J Respir Crit Care Med. 2018;197(1):117-26.

8. Sunwoo BY, Light M, Malhotra A. Strategies to augment adherence in the management of sleep-disordered breathing. Respirology. 2020 Apr;25(4):363-71. doi:10.1111/resp.13589.

9. Mehrtash M, Bakker JP, Ayas N. Predictors of Continuous Positive Airway Pressure Adherence in Patients with Obstructive Sleep Apnea. Lung. 2019 Apr;197(2):115-21. doi:10.1007/s00408-018-00193-1.

10. Poulet C, Veale D, Arnol N, Lévy P, Pepin JL, Tyrrell J. Psychological variables as predictors of adherence to treatment by continuous positive airway pressure. Sleep Med. 2009 Oct;10(9):993-9. doi:10.1016/j.sleep.2009.01.007.

11. Bakker JP, Rui Wang R, Jia Weng J, et al. Motivational enhancement for increasing adherence to CPAP: A randomized controlled trial. Chest. 2016;150(2):337-45.

12. Rudilla D, Landete P, Zamora E, Roman A, Vergara I, Ancochea J. MEntA Program Based on Motivational Interview to Improve Adherence to Treatment of Obstructive Sleep Apnea With Continuous Positive Airway Pressure (CPAP): A Randomized Controlled Trial. Open Respiratory Archives. 2021;3:100088.

Doi:doi.org/10.1016/j.opresp.2021.100088.

13. Rudilla D, Galiana L, Landete P, et al. Development and validation of the OSA-CPAP perceived competence evaluationinterview. Arch Bronconeumol 2020; Sep 15.S0300-2896(20)30258-1. doi:

10.1016/j.arbres.2020.07.023.

14. Prochaska JO, DiClemente CC. Transtheoretical Therapy: Towards a more integrative model of change. Psychotherapy: Theory Research Practice. 1982;19(3):276-88.

15. Chiner E, Arriero JM, Signes-Costa J, Marco J, Fuentes I. Validación de la versión española del test de somnolencia Epworth en pacientes con síndrome de apnea de sueño Arch Bronconeumol. 1999 Oct;35(9):422-7. doi: 10.1016/s0300-2896(15)30037-5.

16. Spanish Group of Breathing Sleep Disorders. Masa JF, Jiménez A, Durán J, et al. Visual analogical well-being scale for sleep apnea patients: validity and responsiveness: a test for clinical practice. Sleep Breath. 2011;15(3):549-59.

17. Lo Bue A, Salvaggio A, lacono Isidoro S, et al. OSA and CPAP therapy: effect of gender, somnolence, and treatment adherence on health-related quality of life. Sleep Breath. 2020;24(2):533-40.

18. Rotenberg BW, Murariu D, Pang KP. Trends in CPAP adherence over twenty years of data collection: a flattened curve. J Otolaryngol Head Neck Surg. 2016;45(1):43.

19. Olsen S, Smith SS, Oei TP, et al. Motivational interviewing (MINT) improves continuous positive airway pressure (CPAP) acceptance and adherence: a randomized controlled trial. J Consult Clin Psychol. 2012;80(1):151-63.

20. Park CE, Shin SY, Lee KH, et al. The effect of allergic rhinitis on the degree of stress, fatigue and quality of life in OSA patients. Eur Arch Otorhinolaryngol. 2012;269(9):2061-4.

21. Budhiraja R, Parthasarathy S, Drake CL, et al. Early CPAP use identifies subsequent adherence to CPAP therapy. Sleep. 2007;30(3):320-4. 
22. Batool-Anwar S, Baldwin CM, Fass S, et al. Role of spousal involvement in continuous positive airway pressure (cpap) adherence in patients with obstructive sleep apnea (OSA). Southwest J Pulm Crit Care. 2017;14(5):21327.

23. Weaver T. Novel Aspects of CPAP Treatment and Interventions to Improve CPAP Adherence. J Clin Med. 2019 Dec;8(12):2220. doi:10.3390/jcm8122220.

24. Schoch OD, Baty F, Boesch M, Benz G, Niedermann J, Brutsche MH. Telemedicine for Continuous Positive Airway Pressure in Sleep Apnea. A Randomized, Controlled Study. Ann Am Thorac Soc. 2019 Dec;16(12):1550-7. doi:10.1513/AnnalsATS.201901-0130C.

25. Aloia MS, Di Dio L, Ilniczky N, et al. Improving compliance with nasal CPAP and vigilance in older adults with OAHS. Sleep Breath. 2001;5(1):13-21.

26. Lindson-Hawley N, Thompson TP, Begh R. Motivational interviewing for smoking cessation. Cochrane Database Syst Rev. 2015 Mar;2;(3):CD006936.

27. Kohler M, Smith D, Tippett V, et al. Predictors of long-term compliance with continuous positive airway pressure. Thorax. 2010;65(9):829-32.

28. Wild MR, Engleman HM, Douglas NJ, et al. Can psychological factors help us to determine adherence to CPAP? A prospective study. Eur Respir J. 2004;24(3):461-5.

29. DeMolles DA, Sparrow D, Gottlieb DJ, et al. A pilot trial of a telecommunications system in sleep apnea management. Med Care. 2004;42(8):764-9.

30. Weaver TE, Grunstein RR. Adherence to continuous positive airway pressure therapy: the challenge to effective treatment. Proc Am Thorac Soc. 2008;5(2):173-8.

\section{Figures}




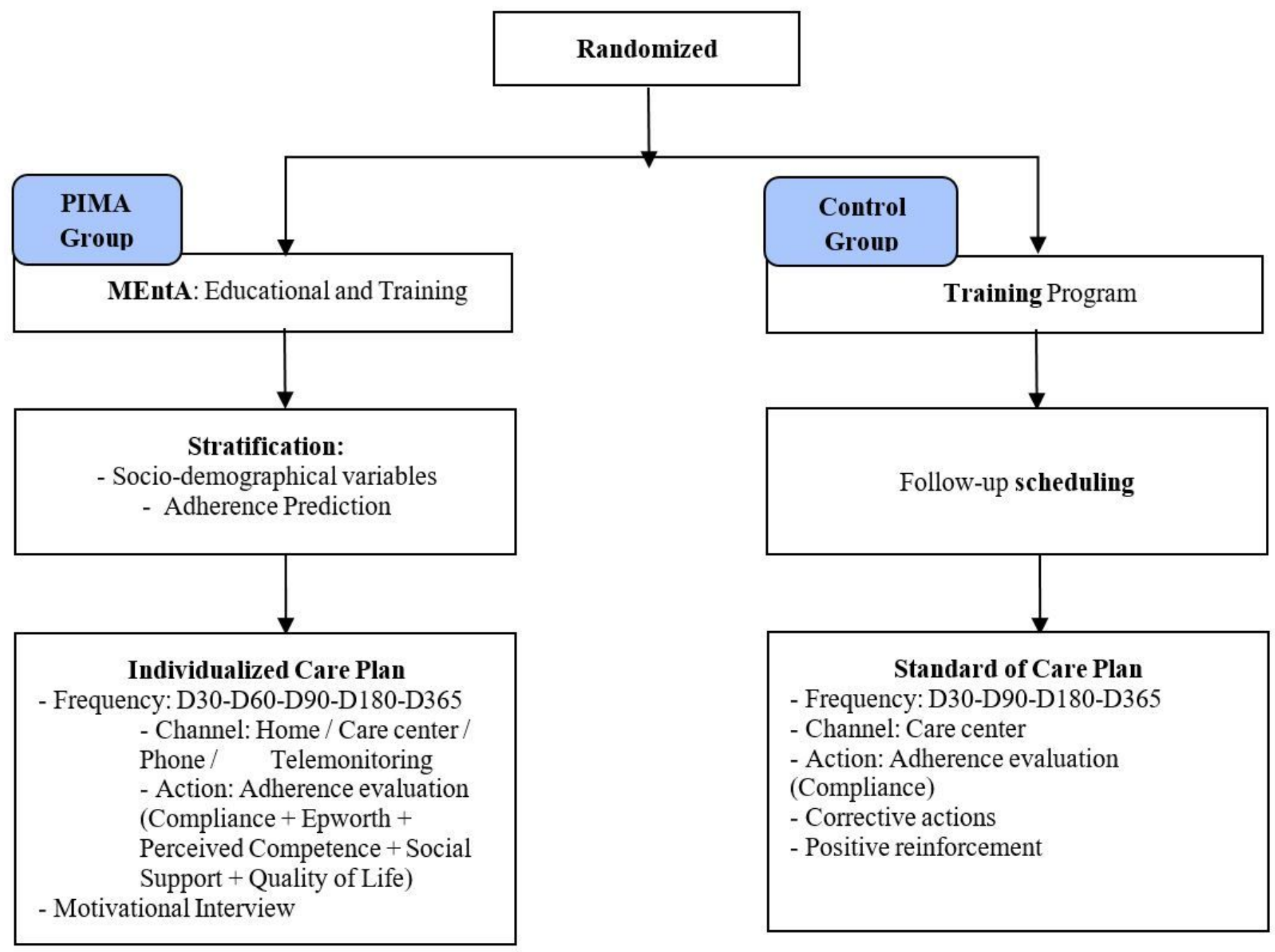

Figure 1

Descriptive diagram of the interventions 


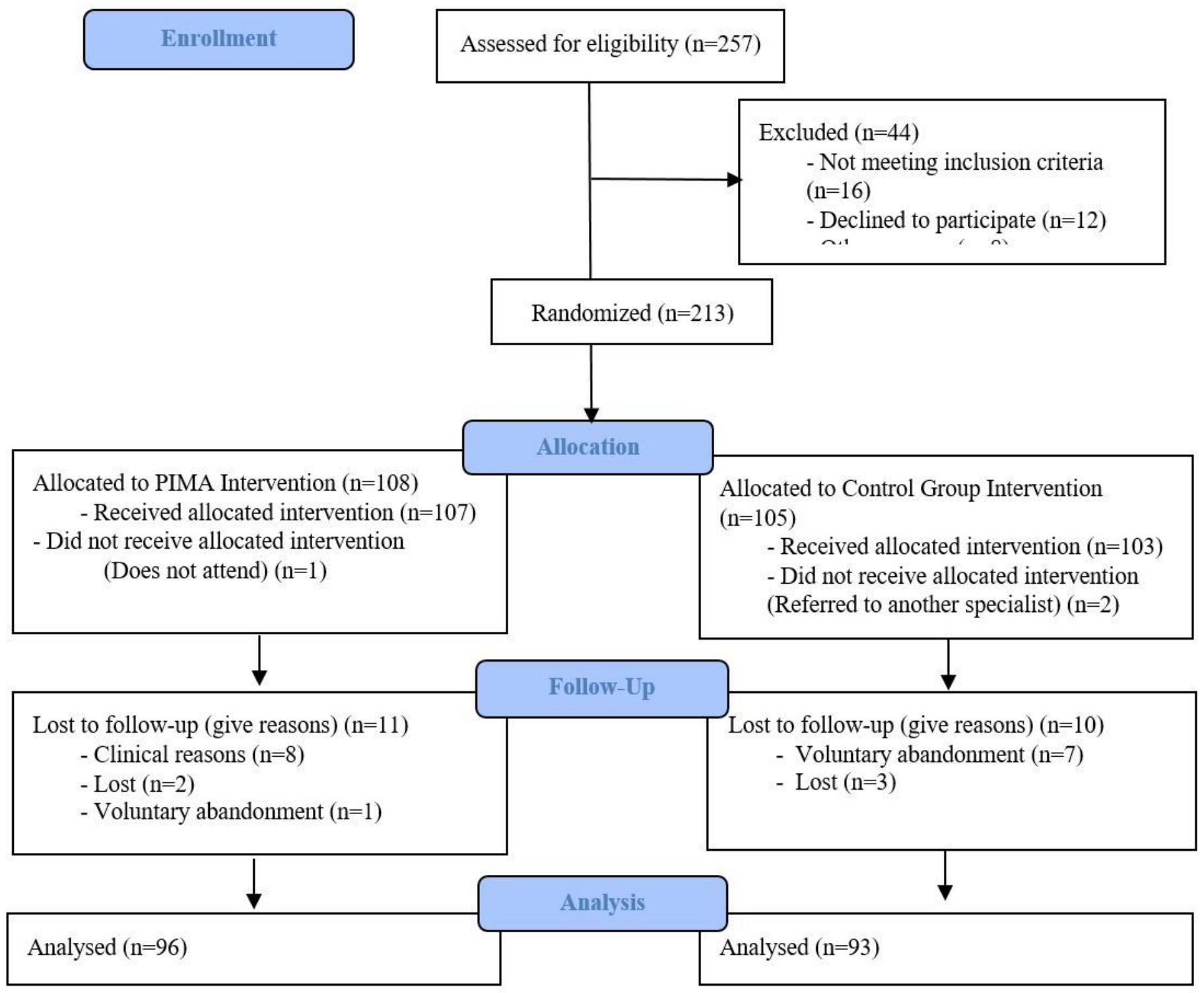

Figure 2

Consort diagram of participants randomized to PIMA and Control Groups 


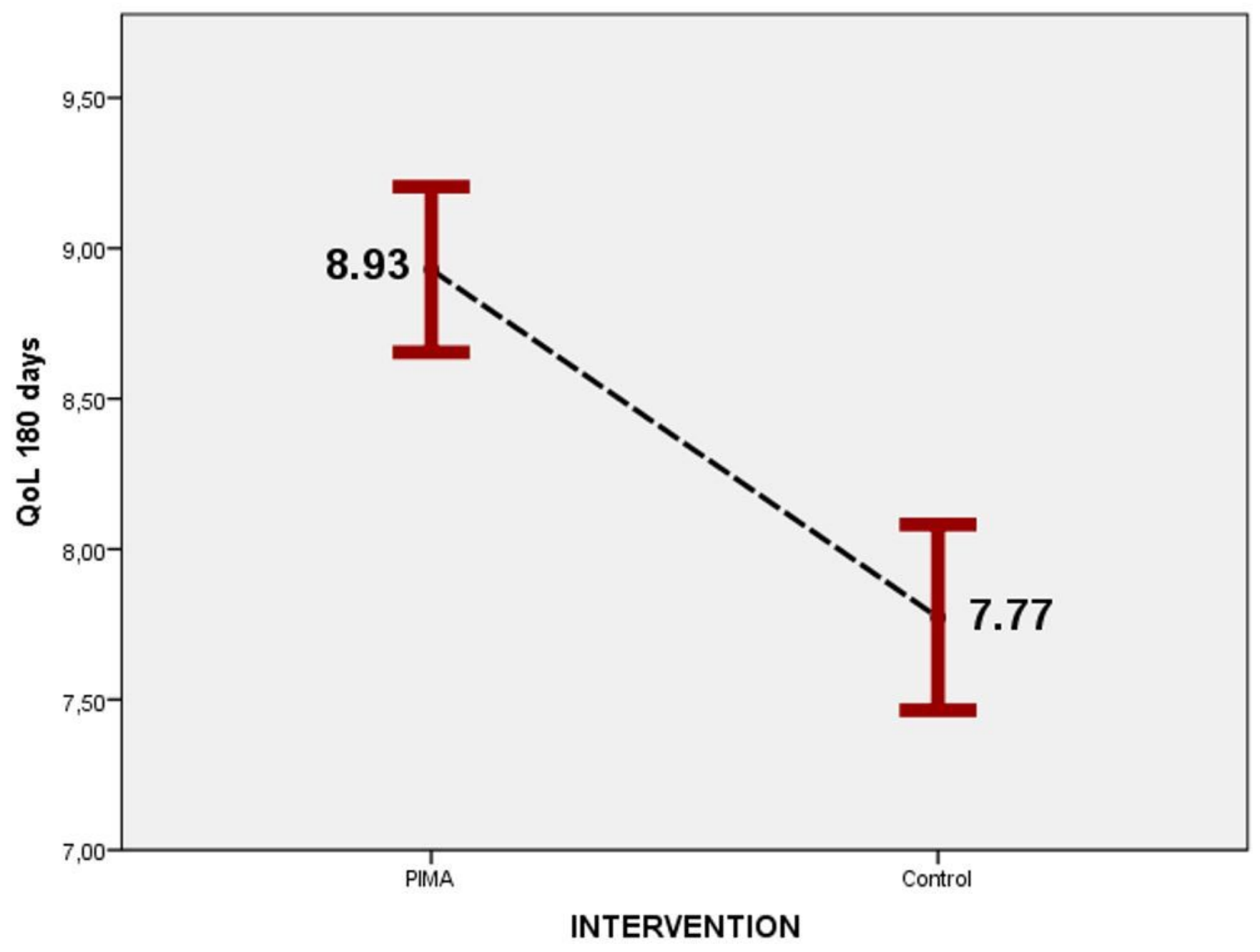

Error Bars: $95 \% \mathrm{Cl}$

Figure 3

Quality of Life at 180 days. 


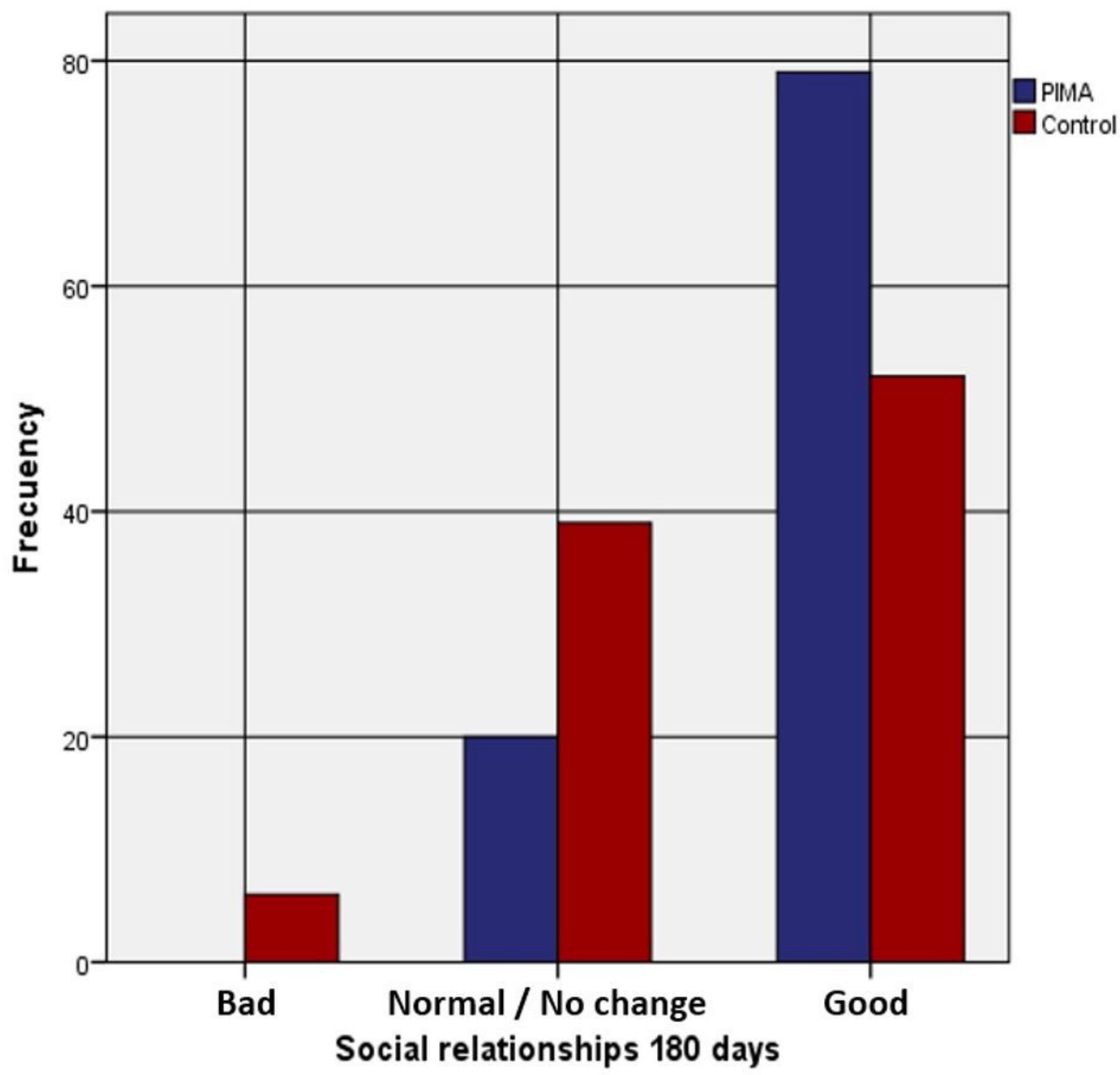

Figure 4

Frequency of social relationship between PIMA and control groups at 180 days by categories.

\section{Supplementary Files}

This is a list of supplementary files associated with this preprint. Click to download.

- CONSORT2010ChecklistPIMA1.doc 